\title{
Особенности эволюции электроразрядной кавитации в магнитном поле
}

\author{
*А. П. Малюшевская, П. П. Малюшевский \\ Институт импульсных процессов и технологий НАН Украины, \\ г. Николаев, 54018, Украина, ${ }^{*}$ e-mail: ninutsa@ukr.net \\ Поступила в редакцию 23.06.2020 \\ После доработки 15.07.2020 \\ Принята к публикации 22.07.2020
}

\begin{abstract}
Исследовано развитие электроразрядной кавитации в жидкой рабочей среде (воде, водных электролитах), помещенной во внешнее магнитное поле. Рассмотрены основные стадии электрического разряда в водной среде при влиянии внешнего магнитного поля на разрядный промежуток. Проведен теоретический анализ предварительных условий для воздействия магнитного поля на развитие электрического разряда в водных средах. Экспериментальные данные, полученные с помощью скоростной фоторегистрации и измерения интенсивности кавитации йодометрическим способом, позволили предложить концепцию управления электроразрядными кавитационными процессами путем влияния внешних магнитных полей.
\end{abstract}

Ключевые слова: электрический разряд, водный раствор, магнитное поле, кавитация

УДК 542.61:537.312.7:537.63

https://doi.org/10.52577/eom.2021.57.2.25

\section{ВВЕДЕНИЕ}

Физический
электроразрядной
кавитации (ЭРНОКейной возникновения
нбъемной
ческого разряда в жидкости, обеспечивающего ее
возникновение, обсуждаются давно и в общих
чертах понятны [1-4], однако всестороннее
понимание этого явления еще не выработано. Изучение электроразрядной кавитации в жидкости продолжается, но идет сравнительно медленно и поэтапно, хотя неуклонно и с нарастающей динамикой [5-9].

Несмотря на значительный прогресс и внедрение электроразрядного кавитационного воздействия в различные методы обработки материалов, «белыми пятнами» остаются некоторые аспекты темы, которые вызывают неподдельный интерес у специалистов - электрофизиков и разработчиков новых электроразрядных технологий. Практическую важность и теоретическую значимость представляют результаты влияния магнитного поля (постоянного, переменного, импульсного) на развитие электроразрядной кавитации в воде и водных растворах, причем в широком диапазоне изменения напряженности. При этом следует отметить, что физическая сущность процессов, происходящих при магнитной обработке самой воды и водных систем, еще не выяснена. Существующие гипотезы сводятся к представлениям об изменении структуры воды под действием магнитного поля, имеется много сведений (весьма противоречивых) об изменениях в магнитном поле таких свойств воды, как вязкость, плотность, электропроводность, поверхностное натяжение, и некоторых других [10-13].

В то же время известно [14], что развитие подводного электрического разряда происходит в четыре стадии - это предпробойная, лидерная, стадия активного преобразования энергии и послеразрядная (в которой уже после полного завершения собственно электрического разряда может существовать и производить работу ЭРНОК). Важнейшая для образования кавитационных областей предпробойная стадия не может быть описана в рамках единой теории, для этой стадии выделяют как минимум четыре различных механизма инициирования разряда: 1) пузырьковыц̆, 2) микровзрывной, 3) ионизачионный, 4) электротепловой. Пробой жидкости как следующая стадия развития разряда и условие, необходимое для возникновения мощной кавитации, также может происходить по существенно разным трем механизмам: быстрому (сверхзвуковому), медленному (дозвуковому) и электротепловому [15]. В первом случае пробой жидкостей также иногда называют ионизационным, во втором пузырьковым, хотя в обоих случаях первоначальное нарушение фазового состояния жидкости происходит за счет движения носителей заряда в самой жидкости, образующихся вследствие ионизации (разряд с анода) или эмиссии и ионизации (разряд с катода), а образование плазменного канала обусловлено ионизацией в газовой фазе. Их особенности обусловлены различием в интенсивности и 
последовательности процессов, обеспечивающих приращение длины плазменного канала, зародившегося на стадии зажигания. А в случаях, имеющих большое влияние на процесс образования кавитационных пузырьков, когда реализуется электротепловой механизм инициирования, пробой включает: разогрев жидкости (преимущественно ионными токами), вскипание жидкости с образованием парогазовых полостей, ионизацию в полости. Разрядный канал удлиняется за счет движения к противоположному электроду области локального разогрева и вскипания жидкости.

Очевидно, что внешнее магнитное поле будет влиять как на процессы, происходящие на стадии зажигания разряда, так и на пробой жидкости. Таким образом, влияние внешнего магнитного поля на процессы, имеющие место во время предпробоя и пробоя жидкости, заслуживает внимательного изучения как с позиции более глубокого понимания физики электроразрядных процессов в жидкости, так и для решения прикладных задач обработки материалов с помощью электроразрядной кавитации.

Цель работы - изучение развития электроразрядной кавитации в жидкой рабочей среде (воде, водных электролитах), помещенной во внешнее магнитное поле.

\section{МЕТОДИКА}

В данной работе приведены некоторые результаты изучения электроразрядной кавитации при ее развитии во времени и в пространстве на всем протяжении от предпробойных явлений в разрядном промежутке до дальних послепробойных во всем объеме электроразрядного реактора. Все приведенные данные получены в основном экспериментальным путем с использованием постоянных магнитов и импульсных сильноточных соленоидов. Эксперименты выполнялись в реакторе, снабженном иллюминаторами, объемом три кубических дециметра с линейными противостоящими электродами, имеющими торцы-полусферы. Аппаратура, использованная в экспериментах, давала возможность наблюдать и регистрировать явления предпробоя и развития электрического разряда в активной стадии, а также далекую послеразрядную стадию. Наблюдения основаны на использовании двух высокоскоростных фоторегистрирующих установок ВФУ-1, которые включались синхронно и обеспечивали наблюдение каждого разряда в водной среде с двух сторон под углом $90^{\circ}$ с временным разрешением от $5 \times 10^{-7}$ с в режиме «лупа времени». Это давало возможность более точно определять траекторию движения стримера, а значит, и его скорость. В качестве подсветки использовалась импульсная лампа ИФК-2000. Переходная оптическая система имела контактирующую с зеркалом воды в разрядной камере линзу и объектив типа «Гелиос-44», проецировала изображение разрядного промежутка в осевой плоскости электродной системы на приемный торец оголовка световода с увеличением $\mathrm{x}_{1,5}$. Микросъемка ВФУ с передающего торца оголовка световода выполнялась в таком режиме, чтобы общее увеличение изображения было одинаковым. Световод представлял собой гибкий стекловолоконный жгут длиной 997 мм и диаметром сечения 14,8 мм, с разрешающей способностью 10 мин/мм, апертурой 0,5, светопропусканием 53\%. Состояние среды в камере на послеразрядной стадии регистрировалось камерой СКС-1М-16.

Импульсное неоднородное электрическое поле создавалось в электродной системе стержень-стержень с вольфрамовыми наконечниками, межэлектродное расстояние варьировалось, напряженность определялась расчетным путем в диапазоне 0,4 до 1 MB/м. Напряжение на разрядном промежутке и ток во внешней цепи основного контура регистрировали с помощью осциллографа С8-2, начальное значение импульса напряжения устанавливалось с помощью киловольтметра C-196.

В изоляторы стержневых противостоящих электродов на расстоянии 5 мм от торцевой поверхности каждого электрода встраивались витки проволочной спирали так, чтобы при разряде образовывался собственно соленоид и разрядный промежуток оказывался точно в его центре, в каждом электроде закладывали по одному - два витка. Центральный стержень электродов в таком случае изготавливался из стальных или медных стержней квадратного сечения со стороной квадрата 4 мм и закругленными ребрами. При этом можно было создавать согласное или встречное магнитные поля электродной системы. Такие индукторы, включаемые в основной разрядный контур, имели серьезный недостаток - с ними исключалась возможность независимого варьирования током в индукторе, а следовательно, и параметрами создаваемых магнитных полей. Исключить этот недостаток удалось применением для питания индуктора отдельного разрядного контура. В таком варианте можно было размещать индуктор (разделенный на две равные секции) поверх изоляторов стержневых электродных систем, собственный разрядный контур позволял получать в соленоиде токи значительной 


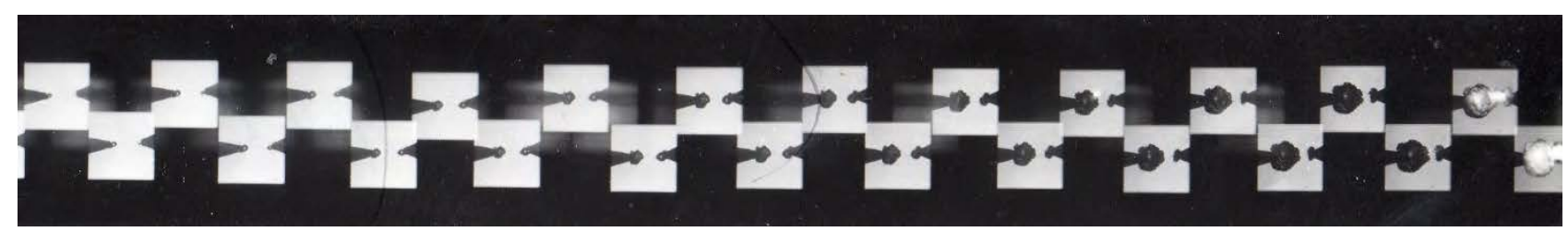

Рис. 1. Развитие разряда в водном растворе ( $\rho=6,9$ Ом·м) в импульсном магнитном поле, время между кадрами - 2,2 мкс, первый кадр соответствует $t=17,6$ мкс, $E=0,873 \mathrm{MB} / \mathrm{M}$.

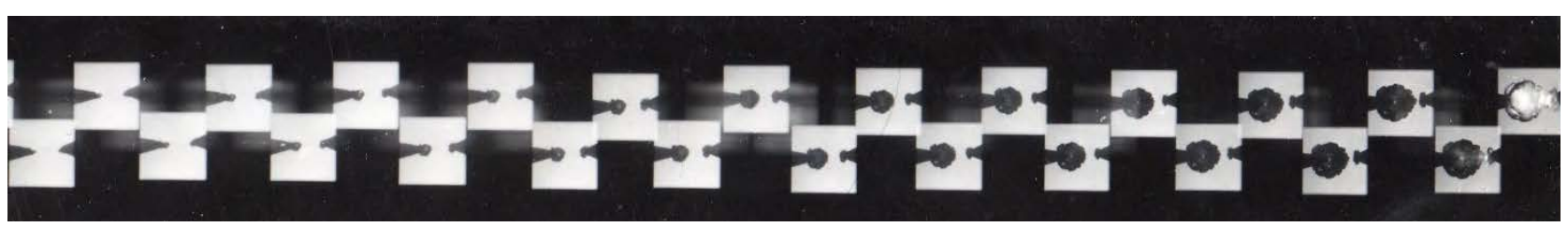

Рис. 2. Развитие разряда в водном растворе ( $\rho=6,9$ Ом·м) без влияния внешнего магнитного поля, время между кадрами 2,2 мкс, первый кадр соответствует $t=11,0$ мкс, $E=0,873 \mathrm{MB} / \mathrm{M}$.

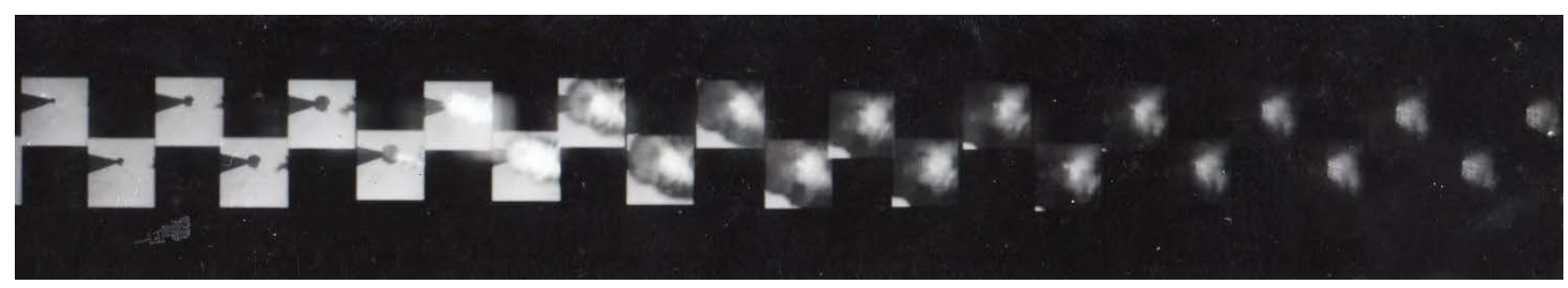

Рис. 3. Развитие разряда в водном растворе $(\rho=6,9$ Ом·м) в постоянном магнитном поле, время между кадрами - 2,22 мкс, первый кадр соответствует $t=6,66$ мкс, $E=1,56 \mathrm{MB} / \mathrm{cm}$.

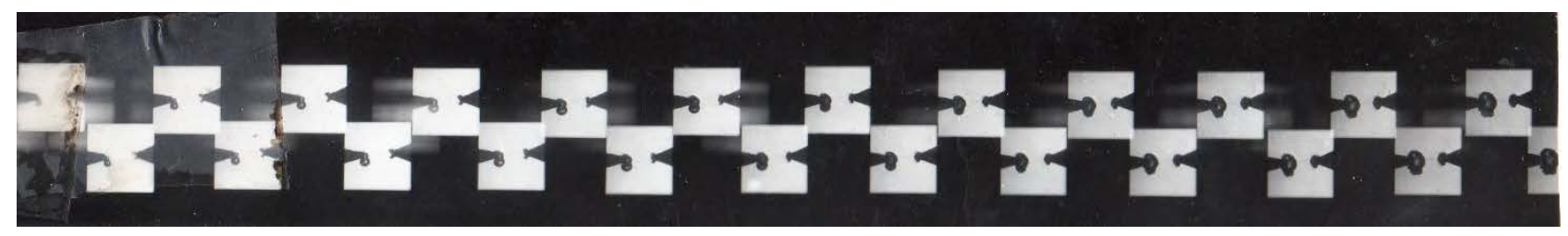

Рис. 4. Развитие разряда в водном растворе ( $\rho=11,6$ Ом·м) в импульсном магнитном поле, время между кадрами - 2,22 мкс, первый кадр соответствует $t=2,22$ мкс, $E=0,625 \mathrm{MB} / \mathrm{cm}$.

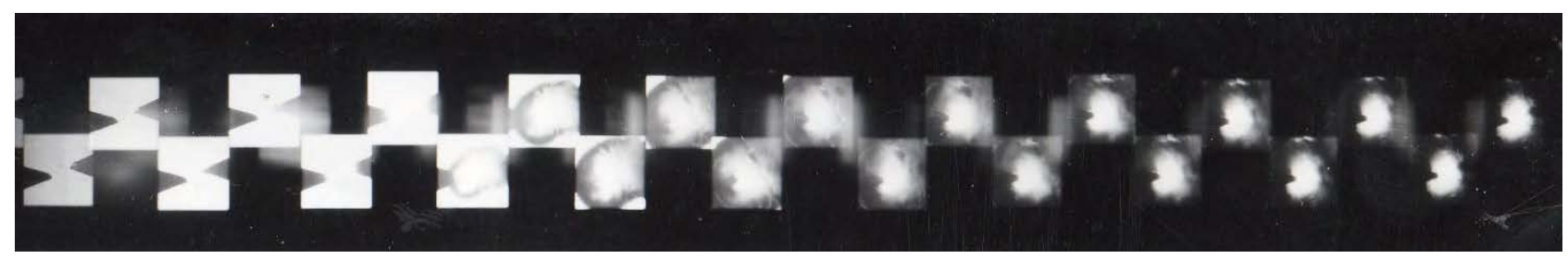

Рис. 5. Развитие разряда в водном растворе ( $\rho=60,4$ Ом·м) в импульсном магнитном поле, время между кадрами - 2,21 мкс, первый кадр соответствует $t=2,21$ мкс, $E=0,686 \mathrm{MB} / \mathrm{cm}$.

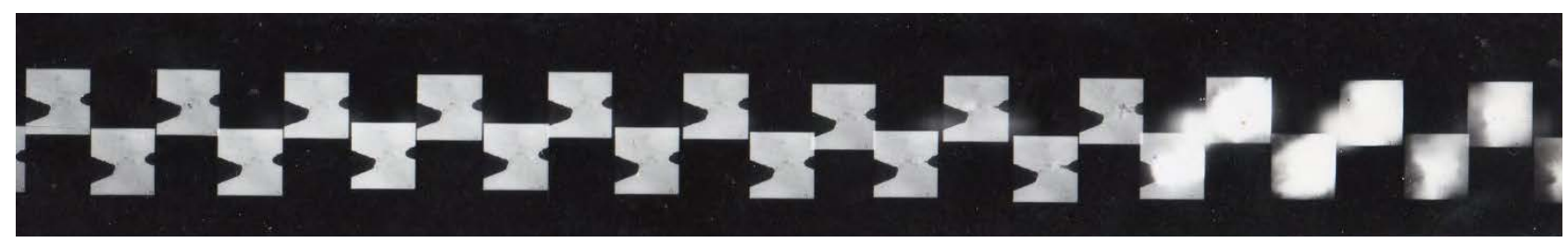

Рис. 6. Развитие разряда в водном растворе ( $\rho=680$ Ом·м) в импульсном магнитном поле, время между кадрами - 2,18 мкс, первый кадр соответствует $t=6,54 \mathrm{м \kappa с,} E=0,417 \mathrm{MB} / \mathrm{cm}$.

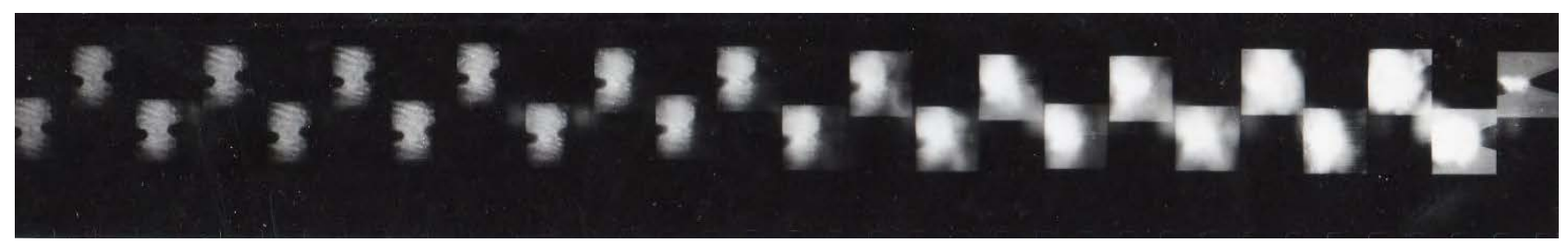

Рис. 7. Развитие разряда в водном растворе ( $\rho=4550$ Ом·м) в импульсном магнитном поле, время между кадрами 2,23 мкс, первый кадр соответствует $t=4,54$ мкс, $E=0,5 \mathrm{MB} / \mathrm{cм}$. 
(до 70 кА) амплитуды и соответственно импульсное магнитное поле с индукцией до 4 Тл.

В качестве постоянных магнитов использовались ферритные пластины толщиной 15 мм прямоугольной $(63$ мм × 83 мм) или круглой (диаметром 86 мм с центральным отверстием диаметром 35 мм) формы, устанавливаемые в специальной оснастке так, чтобы разрядный промежуток стержневой линейной электродной системы оказывался в центральной части постоянного магнитного поля в зоне, удобной для высокоскоростной фоторегистрации. Выбранные постоянные магниты позволяли создавать магнитное поле с магнитной индукцией до 0,2 Тл.

Для экспериментов использовалась деионизированная вода температурой $18-20^{\circ} \mathrm{C}$, электропроводящие свойства воды изменяли добавлением в нее хлористого калия, получая диапазон удельных сопротивлений от 7500 до $6 \mathrm{Oм} \cdot \mathrm{м}$.

Такой важный параметр электроразрядной кавитации, как ее интенсивность, измерялся йодометрическим методом [16].

\section{ЭКСПЕРИМЕНТ}

В ходе эксперимента установлено, что в условиях воздействия внешнего магнитного поля существенно ослабляются процессы газообразования на предпробойной стадии разряда в водных растворах электролитов с удельным сопротивлением от 6,9 до 4550 Ом· м, изменяется характер пробоя разрядного промежутка и впоследствии меняется интенсивность электроразрядной кавитации.

При экспериментальном изучении влияния внешнего импульсного магнитного поля с магнитной индукцией $B=2,2$ Тл на предпробойные процессы в водном растворе с удельным сопротивлением 6,9 Ом•м отмечены следующие особенности: существенное сокращение длительности предпробойной стадии в магнитном поле по сравнению с электроразрядом без дополнительных магнитных влияний, появление газовой фазы как на аноде, так и на катоде - образование пузырьков на катоде примерно в 25-30 раз интенсивнее, чем на аноде (рис. 1, 2).

При воздействии на водный раствор с удельным сопротивлением 6,9 Ом• м постоянного магнитного поля с $B=100$ мТл также зарегистрированы значительно меньшее газообразование и определяющее значение продвижения катодных лидеров для замыкания разрядного промежутка. Здесь скорость их продвижения примерно в 1,4 раза больше в сравнении с процессами без наложения магнитного поля (рис. 3).

Влияние внешнего импульсного магнитного поля с индукцией 2,2 Тл на водный раствор с удельным сопротивлением 11,6 Ом·м отличается интенсивным образованием пузырьков газа и на аноде, и на катоде (рис. 4) и т.д.). Лидеры прорываются сквозь границу раздела фаз на катоде, в то время как на аноде отдельные пузырьки газа объединяются, образуя увеличивающийся пузырь, а появляющийся в начале процесса факелообразный след лидеров также охватывается пузыреобразной структурой. Интересной особенностью пробоя в данной серии является то, что здесь резко увеличивается длительность предпробойной стадии - в среднем она составила около 80 мкс.

А в водном растворе с удельным сопротивлением 60,4 Ом·м при влиянии импульсного магнитного поля с $B=2,2$ Тл предпробойная стадия занимала от 10 до 15 мкс, процесс лидерообразования начинался одновременно и на аноде, и на катоде с появления микропузырьков, сквозь которые затем прорывались катодные лидеры (рис. 5). С анода с меньшей скоростью движется факелообразный след анодных лидеров.

При увеличении удельного сопротивления водного раствора до 680 Ом·м под влиянием внешнего импульсного магнитного поля с индукцией 2,2 Тл с момента подачи импульса в разрядном промежутке появляется оптическая неоднородность, а на 30-й микросекунде с катода начинает двигаться с переменной скоростью факелообразный след лидеров, скорость их продвижения перед завершением пробоя (42 мкс) составляет около 220 м/с (рис. 6). На 37-й микросекунде хорошо видно, что оптическая неоднородность превращается в шнурообразную светящуюся трассу.

В случае исследования предпробойных и пробойных процессов в водном растворе с удельным сопротивлением 4550 Ом•м различие между процессами в магнитном поле и без него особенно ярко выражено (рис. 7). В импульсном магнитном поле с $B=2,2$ Тл уже на второй микросекунде от момента подачи импульса напряжения на разрядный промежуток в нем появляется заметное свечение и к третьей микросекунде пробой завершается.

При аналогичных условиях в отсутствие магнитного поля (рис. 8) слабое свечение в разрядном промежутке появляется также со второй микросекунды, но пробой задерживается до 40 мкс, на катоде появляется, растет и вытягивается в длину микропузырек, превращающийся затем в след лидера, скорость движения которого сильно меняется. 


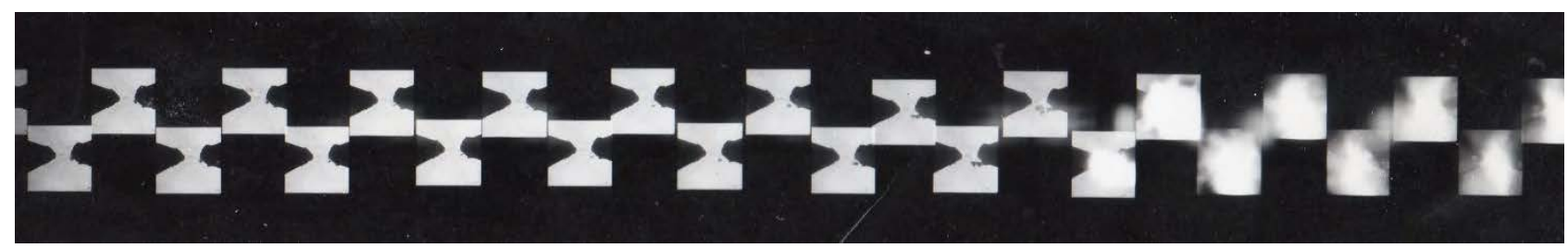

Рис. 8. Развитие разряда в водном растворе $(\rho=4550$ Ом·м) без влияния внешнего магнитного поля, время между кадрами 2,23 мкс, первый кадр соответствует $t=4,46$ мкс, $E=0,5 \mathrm{MB} / \mathrm{cм}$.

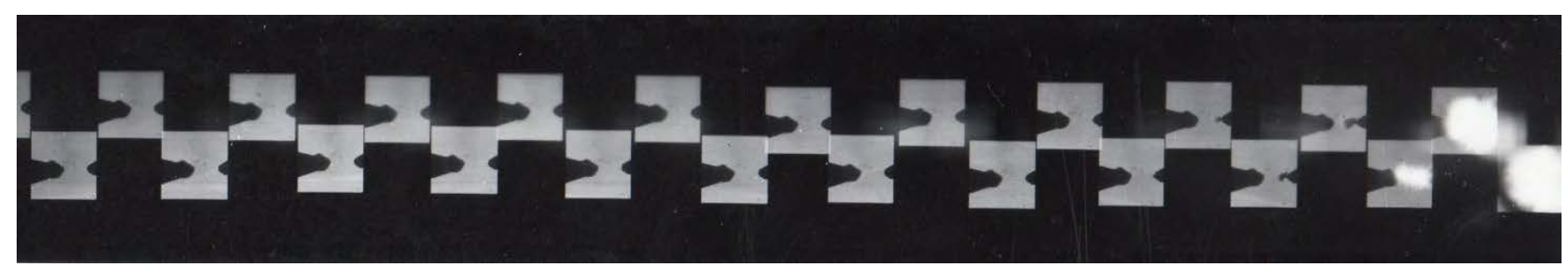

Рис. 9. Развитие разряда в водном растворе ( $\rho=4550$ Ом·м) в постоянном магнитном поле, время между кадрами - 2,22 мкс, первый кадр соответствует $t=8,88$ мкс, $E=0,53 \mathrm{MB} / \mathrm{cm}$.

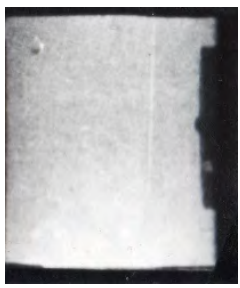

(a)

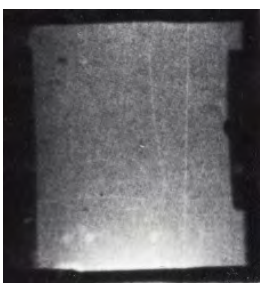

(б)

Рис. 10. Электроразрядная кавитация после пробоя $\left(U_{0}=10\right.$ кВ, $C=0,2$ мкф) водного электролита с начальным удельным сопротивлением 60,4 Ом·м: в импульсном магнитном поле $B=2,2$ Тл (а); без влияния внешнего магнитного поля (б).

Таблица. Интенсивность электроразрядной кавитации в водных электролитах на послеразрядной стадии $\left(U_{0}=10 \mathrm{\kappa B}, C=0,4\right.$ мкф)

\begin{tabular}{|l|c|c|c|c|c|}
\hline \multirow{2}{*}{ Внешнее воздействие } & \multicolumn{5}{|c|}{ Индекс кавитации, \% } \\
\cline { 2 - 6 } & \multicolumn{3}{|c|}{ Удельное сопротивление водного раствора, Ом·м } \\
\cline { 2 - 6 } & 6,9 & 11,6 & 60,4 & 680 & 4550 \\
\hline Нормальное внешнее давление $(0,1 \mathrm{MПа)}$ & 30 & 10 & 16 & 10 & 3 \\
\hline $\begin{array}{l}\text { Нормальное внешнее давление + импульсное } \\
\text { магнитное поле }(B=2,2 \text { Тл) }\end{array}$ & 5 & 27 & 2 & 3 & 3 \\
\hline
\end{tabular}

Для электроразрядных процессов в водном растворе с удельным сопротивлением 4550 Ом·м в постоянном магнитном поле с индукцией 100 мТл характерны полное отсутствие образования пузырьков на электродах и быстрые факелообразные следы катодных лидеров, инициирующих завершение пробоя. Средняя скорость движения лидеров в магнитном поле такого рода в 1,8-2 раза выше, чем при разрядах без влияния внешнего магнитного поля, в обоих случаях отмечается «рывок» катодного лидера на завершающем этапе перекрытия разрядного промежутка (рис. 9).

Описанные явления, наблюдаемые на предпробойной и пробойной стадиях, естественным образом сказываются на процессе развития электроразрядной кавитации на послеразрядной стадии. Например, в водном электролите с удельным сопротивлением 11,6 Ом·м пробой происходит еще по электротепловому механизму, хотя электроразрядная кавитация возбуждается и развивается не активно. А при повышении удельного сопротивления водных

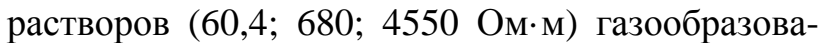
ние на предпробойной стадии существенно и резко уменьшается, и это приводит к преобладанию значения ионизации при пробое разрядного промежутка, а значит, к уменьшению, вплоть до исчезновения, парогазовых зародышей кавитации. Результаты наложения внешнего магнитного поля на интенсивность послеразрядных кавитационных процессов представлены в таблице. Видно, что относительное газосодержание, определяющее количество зародышей кавитации, в магнитном поле резко уменьшается - в среднем в четыре раза по сравнению с относительным газосодержанием в таком же в водном электролите без дополнительного влияния внешних магнитных полей. Объем кавитационной области сокращается (см. рис. 10), что влечет за собой снижение эффективности электроразрядной кавитационной обработки. 
Как видно из приведенных в таблице экспериментальных данных, влияние внешнего магнитного поля на газосодержание весьма существенно. Под его воздействием усиливаются процессы коагуляции и гетерокоагуляции выделяющихся микропузырьков газа и, как следствие, начинается дегазация водного электролита, особенно быстро это происходит в зоне разрядного промежутка, что, в свою очередь, влияет на возникновение и развитие кавитации во всем объеме электроразрядного реактора.

Для того чтобы установить, существуют ли предварительные условия для использования магнитного поля с целью расширения возможностей подводного электрического разряда, необходим теоретический анализ.

\section{ТЕОРИЯ}

Предпробойная стадия разряда в магнитном nоле. При формировании подводного электрического разряда в магнитном поле еще до появления первичных каналов разряда, инициирующих лидеры, движущиеся в разрядном промежутке, магнитное поле оказывает сильное влияние на всю рабочую среду, активно изменяя ее свойства.

Блюменфельд и Гольдфельд [17] обнаружили эффект изменения электропроводности воды и водных электролитов под воздействием электрического и магнитного полей. В работе [18] рассматривается такая качественная картина этого явления.

Протон в водных растворах существует как ион гидроксония $\left(\mathrm{H}_{3} \mathrm{O}^{+}\right)$, и перенос протона по водородному мостику описывается прыжковым механизмом Гротгуса, приводящим к аномальной подвижности избыточного протона:

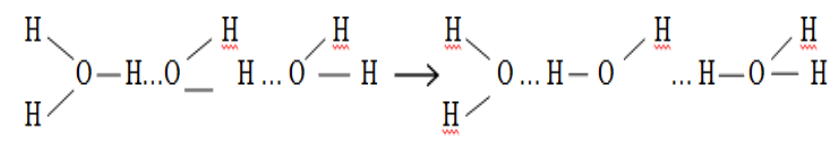

В схеме Гротгуса рассматривается единичная структура, отвечающая процессу переноса протона в системе $\mathrm{H}_{2} \mathrm{O}-\mathrm{H}$... О - Н. Туннелирование протона в таком водородном мостике моделируется посредством так называемых граничных структур протона и отвечающей им локализации протона в минимумах потенциальной кривой, разделенных энергетическим барьером:<smiles>OO</smiles>

Левая структура соответствует ионной паре $\mathrm{H}_{3} \mathrm{O}^{+} \ldots \mathrm{OH}^{-}$, правая - димеру воды.
В опыте Блюменфельда и Гольдфельда включение постоянного тока приводило к поляризации водородных связей и эстафетному механизму по схеме Гротгуса, а попеременное включение магнитного поля - к ослаблению туннельного перехода.

Таким образом, разрядный промежуток длиной $l_{p}$, помещенный в локальное магнитное поле, за счет изменения кинетики движения заряженных частиц должен изменять сопротивление, а последнее играет существенную роль в начальные моменты процесса развития разряда.

Появление свечения в разрядном промежутке еще в долидерной стадии пробоя, отмеченное нами в экспериментах, свидетельствует о быстрых процессах, а обычно предполагают, что время туннельного перехода составляет $10^{-7}-10^{-12}$ с. Позже начинающиеся тепловые процессы, связанные с развитием токов проводимости, появлением газовой фазы, ионизацией в газовой фазе, тормозят ранее начавшиеся ионизационные, отбирая энергию. Подтормаживаемый магнитным полем протон должен активизировать эти начальные электрические процессы, ускорить наступление электрического пробоя до начала развития инерционных тепловых процессов ионизацией сразу вдоль всей светящейся трассы, соединяющей электроды. Есть некоторая вероятность, что зарегистрированное нами на самых ранних стадиях развития разряда свечение может появляться и за счет других явлений, например молекулярных переходов в реакциях окиси азота со свободными атомами кислорода (в воде всегда содержится растворенный воздух). Эта реакция сопровождается излучением непрерывного спектра с максимумом в желто-зеленой области (550-570 нм) [19]. Однако такие реакции вряд ли могут приводить к электрическому пробою воды.

Способствовать быстрому пробою воды и водных электролитов магнитное поле может также за счет «разрыхления» ее структуры в определенных областях с одновременным уплотнением в других. Рассмотрим траектории движения ионов гидроксила $\mathrm{OH}^{-}$и гидроксония $\mathrm{H}_{3} \mathrm{O}^{+}$, которые всегда присутствуют в воде, под действием электрического поля во внешнем магнитном поле напряженностью $H$. Их траектории представляют собой циклоиду. Это движение можно разложить на поступательное и вращательное с радиусом, пропорциональным $m v / e H$, где $m$ - масса иона, $v$ - скорость иона, е - заряд иона. Поскольку молекулы воды обладают большим дипольным моментом, то ионы $\mathrm{OH}^{-}$и $\mathrm{H}_{3} \mathrm{O}^{+}$, двигаясь из одной точки, в которой они возникают при распаде димера, и вращаясь в одной плоскости, 


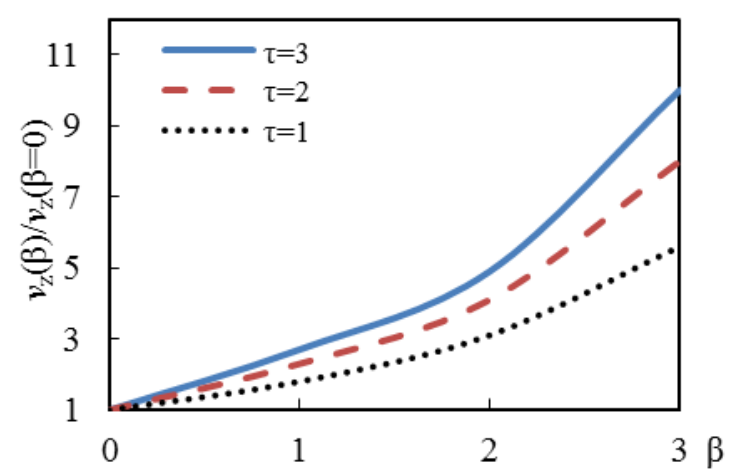

Рис. 11. Характер изменения продольной скорости лидера.

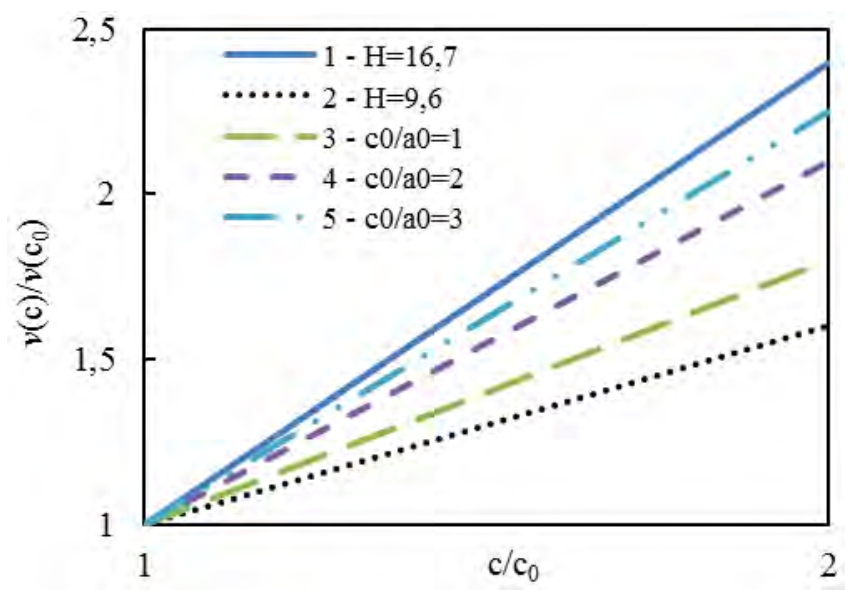

Рис. 12. Зависимости продольной скорости лидера от его длины.

но в противоположные стороны, будут ориентировать ближайшие молекулы воды. В результате происходит объединение молекул в ассоциаты с несколько большей плотностью, но пространство между ассоциатами становится менее плотным. Ассоциаты, конечно, очень пассивны, поскольку неполярны, нейтральны и малоподвижны из-за больших размеров и массы. В «рыхлом» же пространстве между ними, наоборот, процессы пробоя облегчаются, и следует ожидать ускорения ионизационных процессов.

Лидерная стадия разряда в магнитном поле. Рассмотрим, следуя работам Фирсова и Лозанского [20, 21], проводящий плазменный лидер с головкой сфероидальной формы с полуосями $(a, a, c)$ в магнитном поле $H(0,0, H)$. Из работ $[22,23]$ следует, что величина напряженности электрического поля в жидкости вблизи головки лидера (точка $x=0, y=0, z=C$ ) не зависит от напряженности магнитного поля и определяется выражением:

$$
E_{1 z}(0,0, C)=\frac{E_{1 z}(\infty)}{n^{(z)}+\frac{\sigma_{1}}{\sigma_{2}}(1-n)},
$$

где $E_{1 z}(\infty)=$ const - значение напряженности однородного электрического поля вдали от лидера, приложенного в направлении $\vec{H}\left[\vec{E}_{1}(\infty)=\left(0,0, E_{1 z}(\infty)\right] ; \quad n^{(z)}-\right.$ коэффициент деполяризации сфероида вдоль оси $z(\vec{H} \| z)$; $\sigma_{1}, \sigma_{2}-$ проводимость жидкости и продольная проводимость плазмы в магнитном поле.

Тогда продольная скорость продвижения идеально проводящего лидера $v_{z}=d c / d t=\mu_{e} E_{1 z}, \quad$ равная произведению подвижности электронов вдоль магнитного поля $\mu_{e}$ на напряженность электрического поля у головки лидера, обратно пропорциональна коэффициенту деполяризации $n^{(z)}$, и для средних значений отношения лидера к его радиусу $c / a(1 \leq c / a \leq 10)$ удовлетворительно описывается законом: $v_{z}=3\left(\frac{c}{a}\right)^{5 / 4} \mu_{e} E_{1 z}(\infty)$.

Так как в направлении, поперечном магнитному полю, электрическое поле равно нулю, радиальное расплывание лидера может иметь только диффузный характер и тогда изменение лидера описывается зависимостью:

$$
a=a_{0}+\sqrt{6 D_{\perp} t},
$$

где $a_{0}$ - начальный радиус лидера; $D \perp-$ коэффициент радиальной диффузии; $t$ - время.

В магнитном поле поперечная проводимость, подвижность и коэффициент диффузии зависят от параметра Холла $[12,13]$ плазмы $\beta=\omega \tau$, где $\omega$ - циклотронная частота вращения электрона в магнитном поле, пропорциональная 


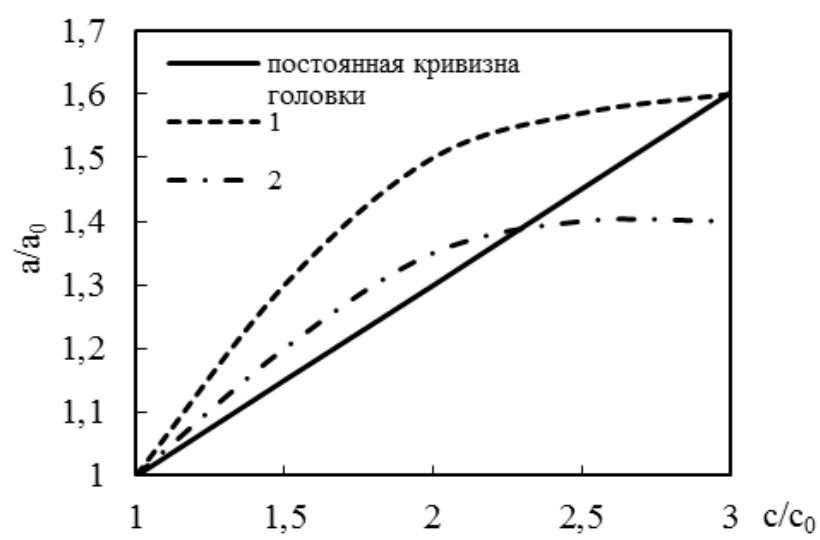

Рис. 13. Зависимость относительного диаметра лидера от его длины.

$H$, а $1 / \tau$ - частота электронных столкновений. При классической диффузии поперечный коэффициент диффузии $D_{e \perp}(\beta)$ в магнитном поле уменьшается по закону $D_{e \perp}(\beta)=D_{e} \frac{1}{\sqrt{\left(1+\beta^{2}\right)}}$.

Интегрируя дифференциальное уравнение продольной скорости развития лидера

$$
\frac{d c}{d t}=3 \mu_{e} E_{1 z}(\infty)\left(\frac{c}{a_{0}+\sqrt{6 D_{e \perp}(\beta) t}}\right)^{5 / 4}
$$

с начальным условием $c(t=0)=c_{0}, a(t=0)=a_{0}$, можно получить следующее приближенное выражение для относительной длины лидера $c(t) / c_{0}$ :

$$
\begin{aligned}
& \frac{c(t)}{c_{0}}=\exp \left(6\left(1+\beta^{2}\right) \frac{1 / 2 \mu_{e} E_{1 z}(\infty) t^{*}}{a_{0}} \times\right. \\
& \times\left(\left(1+\beta^{2}\right)^{-1 / 4} \sqrt{\tau}-\ln \left(1+\beta^{2}\right)^{-1 / 4} \sqrt{\tau}\right),
\end{aligned}
$$

здесь $\tau=t / t^{*}$, а $t^{*}=a_{0}^{2} / 6 D_{e \perp}$ при $\beta-$ времени, за которое диаметр лидера в нулевом магнитном поле увеличивается вдвое, равном нулю.

Характер изменения продольной скорости лидера приведен на рис. 11 при $c_{0}=a_{0}$ и $\mu_{e} E_{1 z}(\infty) t^{*} / a_{0}=1$.

Из приведенных данных видно, что сравнительно небольшое изменение скорости расплывания и размера лидера в радиальном направлении при наложении осевого магнитного поля приводит к существенному увеличению длины и продольной скорости распространения лидера. Если предположить, что время устойчивого развития лидера при наличии и в отсутствие магнитного поля одинаково, то это приведет к снижению пробивного напряжения разрядного промежутка при фиксированной его длине или к увеличению максимально возможной пробиваемой длины при заданной напряженности электрического поля.

Сравнение теории и эксперимента по зависимости продольной скорости лидера от его длины показывает, что экспериментальные данные при $H=0$ вполне удовлетворительно описываются зависимостью (4) (рис. 12). Здесь 1, 2 - экспериментальные данные работы [24] по скорости распространения анодной оконечности лидера при давлении 0,1 МПа для напряженности поля 16,7 и 9,6 кВ/см соответственно, а $v\left(c_{0}\right)$ мгновенная скорость лидера при его длине 3 мм. Линии 3, 4 и 5 на рис. 12 представляют собой зависимости относительной скорости лидера, построенные по формуле (4), для $v\left(c_{0}\right)$, определяемой при значениях $c_{0} / a_{0}=1,2$ и 3 соответственно. Индекс «0» соответствует началу отсчета во времени геометрических параметров лидера.

На рис. 13 приведена зависимость относительного диаметра лидера от его длины при $\beta=0$, сплошной линией обозначены результаты, вытекающие из теории лидера с постоянной кривизной головки [20, 21], а штриховыми линиями - данные, вытекающие из теории лидера с переменной кривизной головки для $\mu_{e} E_{1 z}(\infty) t^{*} / a_{0}=1 \quad$ (кривая 1) и $\mu_{e} E_{1 z}(\infty) t^{*} / a_{0}=1,5$ (кривая 2), по концепции наших исследований.

Отметим также, что качественно эффект влияния магнитного поля на основные характеристики начальной стадии разряда имеет одинаковый характер для обеих концепций. Однако если для начальных стадий разряда в воде в магнитном поле проявится аномальная диффузия плазмы поперек магнитного поля, то воздействие магнитного поля может быть сведено на нет и управлять электроразрядом с помощью магнитного поля будет проблематично.

\section{ВЫВОДЫ}

Влияние магнитного поля проявляется для широкого диапазона изменений удельного сопротивления воды и водных растворов электролитов в уменьшении объема образующейся газовой фазы на электродах и в разрядном 
промежутке вплоть до полного ее исчезновения, увеличении скорости электротепловых процессов формирования канала электрического разряда, сокращении числа и поперечных размеров катодных лидеров, а иногда в развитии анодного лидерообразования с одновременным подавленим катодного. Поскольку влияние магнитных полей на предпробойную стадию очень велико и определено, что разряд развивается в условиях подавления процесса генерирования газовой фазы, необходимо установление обратной связи разрядный контурразвивающийся разряд для управления кавитационными режимами электрических разрядов.

\section{ЛИТЕРАТУРА}

1. Малюшевский П.П., Малюшевская А.П., Левда В.И. Электровзрывная нелинейная объемная кавитация в технологических реакторах Часть 1. Электроразрядное генерирование газовой фазы зародышей кавитации. ЭОМ. 2004, № 1, с. 46.

2. Малюшевский П.П., Малюшевская А.П., Левда В.И. Электровзрывная нелинейная объемная кавитация в технологических реакторах. Часть 2. Анализ структуры кавитационных областей. ЭОМ. 2004, № 2, с. 40.

3. Малюшевская А.П., Малюшевский П.П. Оптимизация процесса тонкого электроразрядного диспергирования. ЭОМ. 2019, т. 55, № 3, с. 51. doi:10.5281/zenodo.3244414

4. Malyushevskaya A.P., Malyushevskii P.P. A novel method to control electrical-discharge nonlinear bulk cavitation. Surf. Eng. Appl. Electrochem, 2007, vol. 43, no. 1, p. 59.

5. Boussetta N., Vorobiev E., Reess T., De Ferron A. et al. Scale-up of high voltage electrical discharges for polyphenols extraction from grape pomace: Effect of the dvnamic shock waves. Innov. Food Sci. Emera. Technol., 2012, no. 16, p. 129. doi:10.1016/J.IFSET.2012.05.004

6. Actis Grande G., Giansetti M., Pezzin A., Rovero et al. Mapping of cavitational activity in a pilot plant dyeing equipment. Ultrason. Sonochem, 2015, vol. 27, p. 440. doi:10.1016/J.ULTSONCH.2015.06.004

7. Ijiri M., Shimonishi D., Nakagawa D., Yoshimura T. New water iet cavitation technologv to increase number and size of cavitation bubbles and its effect on pure $\mathrm{Al}$ surface, International J. of Liahtweight Materials and Manufacture, 2018, vol. 1, no. 1, p. 12. doi:10.1016/J.IJLMM.2018.03.003

8. Ihara S., Sakai T., Yoshida Y., Nishivama H. Fundamental characteristics of discharge plasma generated in a water cavitation field, J. Electrostat. 2018, vol. 93, 9 p. 110. doi:10.1016/J.ELSTAT.2018.04.004

9. Zupanc M., Pandur Ž., Perdih T. S., Stopar D. et al. Effects of cavitation on different microorganisms: the current understanding of the mechanisms taking place behind the phenomenon. A review and proposals for further research. Ultrason. Sonochem. 2019, vol. 57, p. 147. doi: 10.1016/J.ULTSONCH.2019.05.009.

10. Chibowski E., Szcześ A. Magnetic water treatment A review of the latest approaches. Chemosphere, 2018, vol. 203, 2 p. 54. doi: 10.1016/J.CHEMOSPHERE.2018.03.160
11. Kabeel A.E., El-Said E.M.S., Dafea S.A. A review of magnetic field effects on flow and heat transfer in liquids: Present status and future potential for studies and applications. Renew. Sust. Enera. Rev., 2015, vol. 45, 4 p. 830-837. doi: 10.1016/J.RSER.2015.02.029

12. Zborowski M., Chalmers J. J. Magnetic Cell Separation. Maanetic formulary. Amsterdam: Elsevier B.V.. 2007， 29-61. doi: 10.1016/S00757535(06)32002-5

13. Livingstone J.D. Driving force: The natural magic of magnets, Cambridge, MA: Harvard University Press, 1996. 334 p.

14. Наугольных К.А., Рой Н.А. Электрические разряды в воде. М.: Наука, 1971. 176 с.

15. Ушаков В.Я. Физика пробоя жидких диэлектриков (История и современное состояние, вклад советских и российских ученых). Известия Томского политехнического университета. 2004, т. 307, № 2, с. 80.

16. Малюшевская А.П., Малюшевский П.П., Ющишина А.Н. Получение целлюлозы из льняного волокна с использованием электроразрядной объемной кавитации. ЭОМ. 2020, т. 56, № 2, с. 49.

17. Блюменфельд Л.А., Гольдфельд М.Г. О двух предельных значениях электропроводности воды и водных растворов электролитов и о переходах между ними, Журнал структурной химии, 1968, т. 9, № 3, с. 379 .

18. Антонченко В.Я., Крячко Е.С., Парасюк О.С. Влияние магнитного поля на перенос протона в системах с водородной связью. Доклады $\mathrm{AH}$ УССР, 1982, т. 7, с. 60.

19. Gaydon A.G. The Spectroscopy Of Flames. Springer, 1974. 412 p.

20. Лозанский Э.Д., Фирсов О.Б. Теория искры. М.: Атомиздат, 1975. 314 с.

21. Lozanskii E.D., Firsov O.B. Qualitative Streamer Theory. J. Exp. Theor. Phys., 1969, vol. 29, no. 2, p. 367.

22. Афиногенов Е.П., Комельков В.С. Эффект динамического барьера при пробое жидких диэлектриков. Электричество. 1995, № 1, с. 21.

23. Бродская Б.Х., Трапидо Г.А. Развитие импульсных разрядов в электролите и их стабилизация. ЭОМ. 1972, № 4, с. 43.

24. Руденко Н.С., Сметанин В.И. Исследование развития стримерного пробоя в больших промежутках. ЖЭТФ. 1971, т. 61, № 1, с. 146.

\section{Summary}

The article is devoted to the study of the electrodischarge cavitation development in a liquid working medium (water, aqueous electrolytes) placed in an external magnetic field. The main stages of an electrodischarge in an aqueous medium under the influence of an external magnetic field on the discharge gap are considered. A theoretical analysis of the preconditions for the magnetic field influence on the development of an electric discharge in aqueous media is implemented. The experimental data obtained using high-speed photographic recording and measuring the cavitation intensity by the iodometric method allowed to propose a concept for controlling electrodischarge cavitational processes by external magnetic fields.

Keywords: electrical discharge, water solution, magnetic field, cavitation 